\title{
Way ahead - Post Covid-19 Lockdown in India
}

These are general guidelines following post COVID 19 lockdown in India prepared by members of Indian Association of Preventive and Social Medicine. It comprises of experts whose expertise is in epidemiology and health statistics.

$$
16-\text { April }-2020
$$

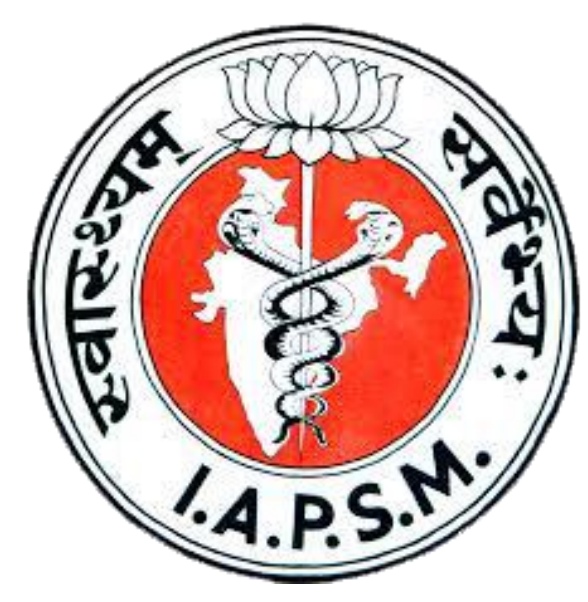

\section{Indian Association of Preventive and Social Medicine}




\section{Contribution for Way ahead - Post Covid-19 lockdown in India}

\begin{tabular}{|c|c|c|c|}
\hline $\begin{array}{c}\text { Sr } \\
\text { No. }\end{array}$ & Name & Designation & Institution \\
\hline 1 & Dr. Manish Rana & $\begin{array}{c}\text { Assistant Professor \& } \\
\text { Treasurer of IAPSM }\end{array}$ & $\begin{array}{c}\text { Department of Community Medicine, GMERS } \\
\text { Medical College, Sola, Ahmedabad }\end{array}$ \\
\hline 2 & Dr. Rashmi Kundapur & Professor & $\begin{array}{c}\text { Department of Community Medicine, K.S. Hegde } \\
\text { Medical Academy, Mangalore }\end{array}$ \\
\hline 3 & Dr. Amir Maroof & Associate Professor & $\begin{array}{c}\text { Department of Community Medicine, University } \\
\text { College of Medical Sciences, Delhi }\end{array}$ \\
\hline 4 & Dr. Vipul Chaudhari & Assistant Professor & $\begin{array}{c}\text { Department of Community Medicine, Government } \\
\text { Medical College, Surat }\end{array}$ \\
\hline
\end{tabular}

\section{Reviewers of Post COVID-19 lockdown in India}

\begin{tabular}{|c|c|c|c|}
\hline $\begin{array}{c}\text { Sr } \\
\text { No. }\end{array}$ & Name & Designation & Institution \\
\hline 1 & $\begin{array}{c}\text { Dr. Amiruddin } \\
\text { Kadri }\end{array}$ & Secretary General & $\begin{array}{c}\text { Indian Association of Preventive } \\
\text { and Social Medicine }\end{array}$ \\
\hline 2 & Dr. Pradeep Kumar & Chief Editor & $\begin{array}{c}\text { Indian Journal of Community } \\
\text { Medicine }\end{array}$ \\
\hline 3 & Dr. Sanjay Zodpey & President & $\begin{array}{c}\text { Indian Association of Preventive } \\
\text { and Social Medicine }\end{array}$ \\
\hline 4 & Dr. Suneela Garg & President Elect & $\begin{array}{c}\text { Indian Association of Preventive and Social } \\
\text { Medicine }\end{array}$ \\
\hline 5 & Dr. Arun Agrawal & Professor & IAPSM Life Member \\
\hline
\end{tabular}

\section{Acknowledgments}

\begin{tabular}{|c|c|c|c|}
\hline $\begin{array}{c}\text { Sr } \\
\text { No. }\end{array}$ & Name & Designation & Institution \\
\hline 1 & Dr. Nirav Bapat & Assistant Professor & $\begin{array}{r}\text { Department of Community Medicine, GMERS } \\
\text { Medical College, Sola, Ahmedabad }\end{array}$ \\
\hline
\end{tabular}




\section{Way ahead - Post Covid-19 Lockdown in India}

COVID 19 pandemic is a global health emergency which every country is grappling with since beginning of this year. Countries have their own strategies to cope with the cases and there have been no universal guidelines or recommendations for same. We commend the Hon. Prime Minister for taking pre-emptive timely measures to contain the pandemic at very beginning of infection in India as sustaining containment measures. Even the World Health Organisation (WHO) has acknowledged India's efforts.

According to experts for effective herd immunity about $60 \%$ of population needs to be infected, after which the infection will slow down and cases will continue to occur at low levels. For that we need good data coming from the system and government shall ensure that good data is provided for monitoring and surveillance.

If all the susceptible population is exposed (without any restrictions) then we have an exponential rise in cases and our health system will be overwhelmed probably resulting in large number of deaths. Great Britain went ahead with strategy of developing herd immunity in its population and safeguarding the elderly but after projections from Imperial College COVID 19 team, reversed their strategy to social distancing and saving lives as their health system will be overwhelmed.

COVID 19 is a mild disease for people in the younger age group while in people above the age of 60 years, the mortality is high. So staggered exposure of younger population to infection while safeguarding the elderly population at home will prevent the surge of cases and facilitate gradual development of immunity in population.

Government should also focus on developing a robust health care system for screening and management of cases coupled with gradual relaxation of restriction so that health system is not overwhelmed with management of COVID 19.

As cases continue to occur in China as well in other countries like Japan and Republic of Korea government shall ensure a system of continuous surveillance and monitoring of the situation on day to day basis till the situation resolves completely. Resurgence of COVID 19 cases may also our country during winter season as predicted by experts and hence adequate planning and preparedness for same is deemed necessary.

Government shall focus on devising a strategy for expansion of facilities for management of COVID 19 cases in line with predicted rapid rise of cases and shall ramp up production of PPE, diagnostic kits, ventilators for effective management of COVID 19 cases in coming days and their requirement will increase with staggered relaxations being implemented.

\section{OBJECTIVES OF THE LOCKDOWN WITHDRAWAL STRATEGY}

1. Expansion of COIVD 19 case management capacity in existing hospitals and new hospitals

2. Reduce speed of spread of the SARS CoV -2 (COVID-19) virus to prevent the surge of infections

3. Prevent overburdening and minimize loss of healthcare professionals

4. Increase capacity for testing as well as COVID 19 testing which will minimize spread in community spread

5. Routine healthcare needs of the population will have to be catered simultaneously

6. Gradually restoring essential commodities, livelihood as well as economy

\section{Categorisation of Districts in 4 Grade of severity}

To facilitate post COVID 19 lockdown activities a 4-grade categorization of district is being proposed as below with relaxation in lockdown for each grade discussed subsequently. The categorization is based on number of cases, spread of cases and health care infrastructure for management of cases based on indicators used for 
global comparison (especially indicators in worst affected countries like US, Europe, Republic of South Korea who have expanded all their existing capacities).

Any District that corresponds to the criteria set based on the following parameters will be accordingly classified. Following parameters are used

1) Number of active cases in last 7 days / million population (Decimal values shall be considered in next higher stage; For the first review on $3^{\text {rd }}$ May, 2020, the relevant period will be 26-4-20 to 2-5-20)

2) Number of active cases in last 14 days / million population (Decimal values shall be considered in next higher stage, For the first review on $3^{\text {rd }}$ May, 2020, the relevant period will be 19-4-20 to 2-5-20)

3) Spread of active cases (\%) = Number of talukas with active cases $\times 100$

Total Number of talukas in district

Geographical/administrative boundaries in that district for taluka/block have to be taken into consideration.

4) Health Infrastructure - Number of beds for COVID 19 per 1000 population

5) Health Infrastructure - Number of critical care beds for COVID 19 per 1000 population (District not having capacity for COVID 19 critical care beds shall make arrangements for same with neighbouring districts)

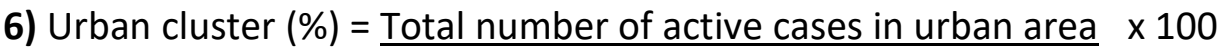

Total number of active cases in districts

\begin{tabular}{|l|l|l|l|l|l|}
\hline \multicolumn{7}{|c|}{ At district level } \\
\hline Sr No & Criteria & Grade I & Grade II & Grade III & Grade IV \\
\hline & $\begin{array}{l}\text { Number of active cases in last 7 } \\
\text { days/ million population }\end{array}$ & $\leq 2$ & $3-5$ & $6-9$ & $\geq 10$ \\
\hline & $\begin{array}{l}\text { Number of active cases in last } \\
14 \text { days/ million population }\end{array}$ & $\leq 5$ & $6-10$ & $11-19$ & $\geq 20$ \\
\hline 3 & Spread of active cases & $\leq 30$ & $31-50$ & $51-70$ & $>70$ \\
\hline 4 & $\begin{array}{l}\text { COVID 19 beds/ 1000 } \\
\text { population }\end{array}$ & $>10$ & $6-10$ & $3-5$ & $\leq 2$ \\
\hline & $\begin{array}{l}\text { COVID 19 critical care beds/ } \\
1000 \text { population }\end{array}$ & $>0.2$ & $0.11-0.2$ & $0.05-0.10$ & $<0.05$ \\
\hline 6 & $\begin{array}{l}\text { Urban clustering of COVID } \\
\text { cases }\end{array}$ & $<30$ & $31-50$ & $51-75$ & $\geq 75$ \\
\hline
\end{tabular}

i. The categorization of a district will correspond to the highest stage obtained in two or more parameters.

ii. District shall review their categorization every week on Sunday and based on the grading status, shall observe the restrictions/ lockdown/containment measures 


\section{Rationale}

If we consider doubling of active COVID 19 cases every 7 days (with strict implementation of restrictions) and simultaneous recovery of COVID 19 cases every 14 days, assuming 10 cases per million population with a bed capacity of 2 per 1000 population, total bed capacity will saturate around $\mathbf{5 8} \mathbf{- 5 9}$ days following the protocols as mentioned in Grade IV. Similarly, for Grade III total bed capacity will saturate around $62-72$ days, for Grade II total bed capacity will saturate around 75 - 86 days and Grade I - total bed capacity will saturate after more than 91 days.

Assuming a decline or plateau of cases after a period of $\mathbf{6 0}$ days; these criteria can be effectively utilized for monitoring the situation post lockdown and ensuring there is no saturation of health system for management of COVID 19.

Similarly, if we assume 10 active COVID 19 cases per million population and doubling rate of 6, 5, 4, 3 \& 2 days respectively, the bed capacity will be saturate as below

\section{Summary report}

\begin{tabular}{|c|c|c|c|c|c|}
\hline \multirow{2}{*}{ No of beds per million \& days of saturation } & \multicolumn{5}{|c|}{$\begin{array}{c}\text { Doubling Period (in Days) assuming } 10 \text { cases/ million } \\
\text { population }\end{array}$} \\
\hline & 6 days & 5 days & 4 days & 3 days & 2 days \\
\hline $\begin{array}{l}\text { Days of saturation for } 1000 \text { beds / Million } \\
\text { population }\end{array}$ & 43 & 36 & 28 & 21 & 15 \\
\hline $\begin{array}{l}\text { Days of saturation for } 2000 \text { beds /Million } \\
\text { population }\end{array}$ & 49 & 41 & 32 & 24 & 16 \\
\hline
\end{tabular}

International Travel - As international travel is suspended and all travellers who have returned are under observation, it is recommended that all international travel remain suspended for another 30 days. Once international travel is resumed the quarantine policy shall be revised accordingly. Any international passenger coming from anywhere by any route shall be quarantined as per national guidelines, preferably at an institutional quarantine still better be tested by the new algorithms of combining IgM and PCR test.

Situation shall be reviewed every 14 days and criteria shall be modified as per the prevailing situation.

\section{Hotspots}

Hotspot shall be identified as a geographical locality (preferably an area of 10000 sq. meters) where there is clustering of $\mathbf{2}$ or more cases and Cordon sanitaire shall be implemented as per standard protocols. The decision and guidelines for same shall be taken by local authorities based on

i. Type of residence (apartments, chawls, slums, etc.)

ii. Population density of cluster

iii. Age structure of population

iv. Accessibility to cluster

v. Community participation 


\section{Common protocols to be followed post lock down}

1. Social distancing-Most important measure to break the chain of transmission and reduce the speed of transmission, social distancing (distance of 2 meters) must be followed and enforced at market places, grocery stores, daily utility stores, public places, govt. offices, banks, electricity bill counters, post offices, health care settings, etc. till the pandemic subsides.

2. Face Mask - a measure to reduce the risk of acquiring infection as well as spread to other susceptible person, policy for strict implementation of mask shall be developed and enforced by government for same.

3. Vulnerable population - People above 60 years of age and those above 50 years of age with presence of comorbidities have a higher risk of mortality and shall remain at home and work from home if possible. Arrangements for providing daily utility items and consumables at home shall be made. Younger close contacts of such elderly individuals should be counseled regarding social distancing from them and avoid touching them.

4. Screening of vulnerable populations - mapping and regular screening of all elderly people (above 60 years of age and those above 50 years of age with presence of comorbidities like Diabetes Mellitus, Cardiovascular diseases, Cancer patients, PLHA, etc.) shall be done for clinical manifestation at least once a week \& preferably twice a week. It can be done using technology and wherever technology is not feasible, physical visits can be employed.

5. Congregation places - Malls, cinema halls, shopping centers, educational institutes, theatres, religious (worship) places, parks, social gatherings, hotels, restaurants, public events (sport, exhibitions, music shows) shall remain closed and barred for next 60 days or till the pandemic subsides. Competent authorities shall review it and make necessary amendments.

6. Essential goods and services - essential goods and services as well as their supply chain shall be reviewed by competent authorities and such establishments shall be made operational as deemed necessary. Special consideration should be given to medical consumables and its supply chain. District Collector, District magistrate and his team shall review it and provided passes to all those individuals involved in these services for a period of 90 days which may be extended further.

7. Public transport - trains, buses, boats, etc. shall be resumed as patients and even health care workers face difficulties in reaching health facilities. They shall be reviewed and made operational by competent authorities on important routes observing strict social distancing and use of mask. Should not exceed the seating capacity of vehicle / locomotive. These services should be run on limited basis and should be extended to people engaged in other essential services such as banking. Online shopping can be allowed for essential goods where the delivery boy will come and deliver goods at colony gates to be collected by the buyers. The list of essential goods needs to be specified.

8. Identity card - All individuals should carry a valid Identity card (Aadhar, Passport Ration Card, Driving License etc.) to prove place of residence and explain purpose of travel.

9. Vehicle movement restriction on Sunday and public holidays -Strict enforcement of restriction of vehicular movement on Sundays and public holidays complying with measures during lockdown.

10. Attendance at marriages and funerals should be restricted to 20 persons and that too only the nearest kith and kin may attend on such occasions.

11. Government offices and banks may reopen with a staggered $\mathbf{5 0} \%$ roster-based attendance over a period of $\mathbf{3 0}$ days and follow a five-day week during the period of the restrictions.

12. Large scale movement of people across international and state boundaries shall be restricted till normalcy seems to prevail. 
13. Any person violating these containment measures will be liable to be prosecuted against as per the provisions of Section 51 to 60 of the Disaster Management Act, 2005.

\section{Grade I - Low Vulnerability (Observed for next 30 days)}

1. Boundaries of urban clusters in district must be sealed and no entry of any person from outside the urban cluster shall be permitted during this phase other than what is permitted currently with a special check on migrant laborer. In district, competent authorities shall monitor and permit movements of people deemed necessary for essential services and other services.

2. Total employees at any work site (other than Government Offices, health care facilities) shall be restricted to $\mathbf{7 0}$ $\%$ of staff strength in a shift as decided by competent authorities. The owner of the establishment will be bound to observe these restrictions. Failure to do so will be tantamount to an offence under relevant provisions of the Epidemic Diseases Act, 1897 and Disaster Management Acts, 2005.

3. Hand sanitizers and hand washing facilities shall be made available for all working staff.

4. Bus / train travel - permitted up to 1 passenger per seat without any standing passengers and on routes approved by competent authorities.

5. Vulnerable population with comorbidities shall be screened once a week

6. Attendance for marriages, funerals shall be restricted to $\mathbf{2 0}$ which shall include nearest kith and kins and competent authorities can permit additional individuals as deemed necessary.

7. Strict Isolation of cases and quarantine of household and close contacts shall be observed as per guidelines.

8. Autos and Taxis may be allowed but restricted to total of one and three passengers respectively. Owners of the vehicles should ensure that hand sanitizers are kept in the vehicles and are made available to the passenger. All occupants in the vehicle should compulsorily wear masks.

Grade II - Moderate Vulnerability (Observed for next 40 days and if conditions improve prior to it, can be revised)

1. Boundaries of urban clusters in district must be sealed and no entry of any person from outside the urban cluster shall be permitted during this phase other than what is permitted currently with a special check on migrant laborer. In district competent authorities shall monitor and permit movements of people deemed necessary for essential services and other services.

2. Total employees at any work site (other than Government Offices, health care facilities) shall be restricted to $\mathbf{5 0}$ $\%$ of staff strength in a shift and production shall be curtailed to maximum of $70 \%$ as decided by competent authorities. The owner of the establishment will be bound to observe these restrictions. Failure to do so will be tantamount to an offence under relevant provisions of the Epidemic Diseases Act, 1897 and Disaster Management Acts, 2005.

3. Hand sanitizers and hand washing facilities shall be made available for all working staff.

4. Bus / train travel - permitted up to 1 passenger per seat without any standing passengers and on routes approved by competent authorities.

5. Vulnerable population with comorbidities shall be screened twice / once a week

6. Attendance for marriages, funerals shall be restricted to $\mathbf{2 0}$ which shall include nearest kith and kins and competent authorities can permit additional individuals as deemed necessary.

7. Strict Isolation of cases and quarantine of household and close contacts shall be observed as per guidelines.

8. Autos and Taxis may be allowed but restricted to total of one and three passengers respectively. Owners of the vehicles should ensure that hand sanitizers are kept in the vehicles and are made available to the passenger. All occupants in the vehicle should compulsorily wear masks. 
Grade III - High Vulnerability (Observed for next 50 days and if conditions improve prior to it, can be revised)

1. Prior to the enforcement of revised lockdown, the boundaries of district or the urban clusters must be sealed and no entry of any person from outside the district shall be permitted during this phase other than what is permitted currently, with a special check on migrant labourers. Competent authorities shall monitor and permit movements of people deemed necessary for essential services.

2. Total employees at any work site (other than Government Offices, health care facilities) shall be restricted to $\mathbf{3 0}$ $\%$ of staff strength in a shift and production shall be curtailed to maximum of $50 \%$ as decided by competent authorities. The owner of the establishment will be bound to observe these restrictions. Failure to do so will be tantamount to an offence under relevant provisions of the Epidemic Diseases Act, 1897 and Disaster Management Acts, 2005.

3. Hand sanitizers and hand washing facilities shall be made available for all working staff.

4. Bus / train travel - permitted up to 1 passenger per seat without any standing passengers and on routes approved by competent authorities.

5. Vulnerable population with comorbidities shall be screened twice / thrice a week

6. Attendance for marriages, funerals shall be restricted to $\mathbf{2 0}$ and shall include nearest kith and kins.

7. Strict Isolation of cases and quarantine of household and close contacts shall be observed as per guidelines.

Grade IV - Extreme Vulnerability (Observed for next 60 days and if conditions improve prior to it, can be revised)

1. Prior to the enforcement of revised lockdown, the boundaries of district or the urban clusters must be sealed and no entry of any person from outside the district shall be permitted during this phase other than what is permitted currently, with a special check on migrant laborer.

2. Total employees at any work site (other than Government Offices, health care facilities) shall be restricted to $\mathbf{2 0}$ $\%$ of staff strength in a shift and production shall be curtailed to maximum of $30-50 \%$ as decided by competent authorities. The owner of the establishment will be bound to observe these restrictions. Failure to do so will be tantamount to an offence under relevant provisions of the Epidemic Diseases Act, 1897 and Disaster Management Acts, 2005.

3. Hand sanitizers and hand washing facilities shall be made available for all working staff.

4. Bus / train travel - permitted up to 1 passenger per seat without any standing passengers and on routes approved by competent authorities and must be highly restricted.

5. Vulnerable population with comorbidities shall be screened twice / thrice a week

6. Attendance for marriages, funerals shall be restricted to $\mathbf{2 0}$ and shall include nearest kith and kins.

7. Strict Isolation of cases and quarantine of household and close contacts shall be observed as per guidelines.

IAPSM also perceives need for resumption of routine medical services as below

1) Keeping pandemic in view, routine medical services which comprise of $70 \%$ of outpatient care are compromised

2) Majority of hospitals are functioning at 30\% capacity or even less as far as routine medical services are concerned resulting in sustainability issues in private sector as well.

3) Across nations NON-COVID hospitals should also have a fever screening OPD as per guidelines of Government of India ensuring social distancing and use of mask with adequate hand washing facilities.

4) Utilization of Mobile technology and tele medicine shall be expanded and aggressively promoted. 
5) Hospitals must have a strategy for patients communication with regards for follow up to limit physical visits of patients as far as feasible and allay anxiety.

6) FAQs based on most common queries is already there but new may be added as per concerns raised by public so as to ensure that a common message is given from all health care providers.

7) Healthcare workers have been infected and hospitals and healthcare establishments are being put under quarantine/sealing. This is creating panic like situation and overcrowding of other already overburdened public health care facilities. It has also resulted in stigma towards hospital which are quarantined or sealed. Healthcare professionals have anxiety and fear resulting from closure of stand-alone clinics and healthcare facilities in private sector. Hence hospitals should not be sealed or put under quarantine but rather complete decontamination of the organization using rapid disinfection technology as being done for OTs and ICU shall be employed and hospital or facility should reopen in a day or two or as early as possible.

8) Continuous training and capacity building healthcare professionals is must to allay their anxiety/fear of health care providers. Community Medicine departments have critical role in trainings but use of digital platforms can be made along with associations like IMA, IAP, FOGSI etc. Accredited hospitals can take up this responsibility to train smaller $\mathrm{HC}$ facilities /clinics in their vicinity.

9) Adequate, effective security of HCFs and staff to be ensured in the field and hospital settings by involving district level administrative functionaries.

10) Separate hospitals for COVID 19 patients with different flow area away from routine patients has to be ensured. Suspected cases to be referred and transported to nearby COVID 19 hospital with full precautions in a safe manner.

11) Keeping in view the financial hardships faced by HCWs and frontline workers, it becomes imperative to timely release salaries and compensations to ASHAs, ICDS and all health care professional.

12) Resumption of field level health activities - maternal \& child health services as well as other services ensuring social distancing and use of mask.

\section{Citation}

Rana M, Kundapur R, Maroof A, Chaudhari V, Kadri A, Kumar P, Zodpey S, Agrawal A, Bapat N. Way ahead - Post Covid-19 Lockdown in India. Indian J Comm Health. 2020;32(2-Special Issue):175-183. (The document is available in public domain) 